\title{
RESEARCH OF THE AWARENESS AND PREPAREDNESS FOR FLOODS OF FOREIGNERS TEMPORARILY RESIDING IN BULGARIA (VARNA)
}

\author{
Hristianna ROMANOVA \\ Medical University, Varna, Bulgaria \\ romanova_hr@abv.bg \\ Todor YOTOV \\ Medical University, Varna, Bulgaria \\ todor_yotov@hotmail.com \\ Vili ZAHARIEV \\ Medical University, Sofia, Bulgaria \\ vilislavchev@abv.bg
}

\begin{abstract}
A survey of 230 young people from 12 countries from Europe and Asia has been made. A high percentage of respondents (42\%) have experienced a flood. Most respondents (64.6\%) have not been informed whether they live in a flood-risk area. Self-assessment of respondents' ability to provide first aid in flood situations is high $(75 \%)$, but the overall disaster preparedness is low because $78.9 \%$ of respondents say they feel unprepared. The awareness and readiness of the studied group of 230 young foreigners temporarily residing the country are evaluated as follows: very good in providing CPR; with a good knowledge of flood epidemic consequences 80 $\%$ will take effective measures against the risk of intestinal contagious disease, and $81.5 \%$ will be saved from drowning because they can swim; lower, but still good preparedness for wound and arterial bleeding first aid (close to $40 \%$ ), mechanisms of contamination transmission by means of objects (33,3\%), use of disinfectants in the case of epidemics (45,4\%); very low readiness for rapid evacuation incases of floods and other disasters (only $5.3 \%$ have a bug-out bag), etc.
\end{abstract}

KEYWORDS: flood, heavy rainfall, topogenic disasters, preparedness, awareness

\section{Introduction}

Flood is one of the most common natural disasters, both globally and in Bulgaria. The most frequent floods are of rainy-river type. Of all ecological catastrophes, floods are the best explored and known to humans (Kostadinov, 2010).

Flood is a natural disaster where large territories are covered with water due to increased water level of rivers, lakes or seas. Intensive rainfall, snow melting, dam breaking, high waves, etc. are part of the reasons for raising the level of water basins.

This phenomenon can cause significant material damage and cause epidemics. The flood threatens the property and the lives of people.

Due to the scale of this phenomenon, each country has measures against flooding, the possible cases for their occurrence are analyzed and their risk is assessed (Romanova, Radeva, Marinova, Marinov \& 
Bozova, 2012). Plans for proper reaction in a case of flooding are also being developed and different kinds of research are being carried out, requiring the proper professional readiness of the state emergency agencies for acting in extreme disaster situations (Krastev \& Angelov, 2016).

According to most authors (KhorramManesh, 2017; Radeva, 2019), this disaster can be categorized as follows:

- Natural - caused by overflowing rivers.

- Torrential - caused by heavy rainfall - over $30 \mathrm{l} / \mathrm{m}^{2}$ or intensive snow melting.

- Marine - caused by tsunami and storm waves.

- Technogenic - caused by accidents, improper management of hydrotechnical facilities, deliberate actions, destruction of dam walls, etc.

The purpose of this research is to study the awareness and preparedness of young foreigners temporarily residing in Varna, Bulgaria for reactions in cases of flooding.

\section{Materials and Methods}

A sociological method has been used to study the awareness and preparedness for floods of foreign citizens residing in the Republic of Bulgaria.

The method chosen is an anonymous consultation using a questionnaire completed by the respondents personally.

The reliability of the individual primary information is high. The survey has been conducted with 230 young people aged 18-34.

The questionnaire includes 32 questions. In 14 questions, all possible answers have been clarified and formulated in advance, 2 questions are open and 16 are combined, thus giving the opportunity for a sharing opinions and giving suggestions and clarifications. The principles of anonymity and impartiality to certain persons, qualities and nationalities are observed.

Questions refer to:

- respondent's personal characteristics (age, gender, education, place of residence);

- subjective assessment of preparedness for floods and providing first aid;

- an objective assessment of the awareness and readiness of foreign citizens temporarily residing in Bulgaria in 20182019.

\section{Results and Discussion}

$44.7 \%$ male and $55.3 \%$ female respondents have been interviewed. Of them $23.1 \%$ with secondary education, $23.1 \%$ with college education, and $53.3 \%$ with higher educational status.

227 responded that during the interview they were residing in the town of Varna.

The question, "Which of the disasters have you experienced?", has received the following answers (the highest percentage have survived a flood $-42 \%$ ) - Figure no. 1 .

$10.6 \%$ have reported that they have not experienced any of these disaster situations. Nearly one-third have mentioned they have experienced more than one disaster.

The majority of respondents $(64.6 \%)$ have not informed themselves whether they live permanently in a flood-risk area.

It is worth mentioning that the percentage of disaster insurances (including floods $-44.1 \%$ ) is high, but only $5.3 \%$ have a prepared bag with documents and food (bug-out bag) and maintain readiness to evacuate in case of disasters (including floods).

The respondents' self-assessment of their ability to provide first aid (cardio-pulmonary resuscitation - CPR) is very high $-75 \%$ have responded positively Figure no. 2. 


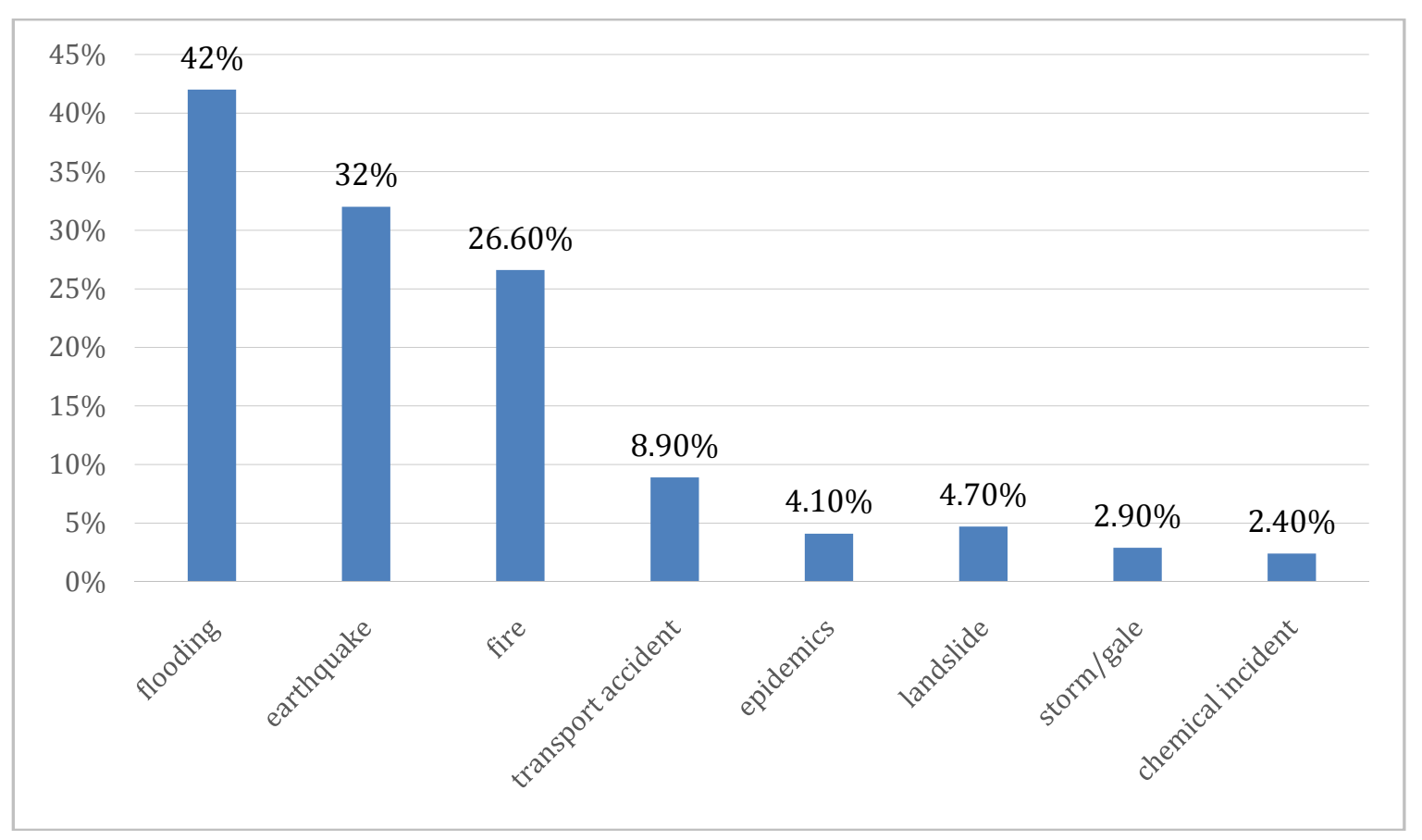

Figure no. 1: Which of the disasters have you experienced?

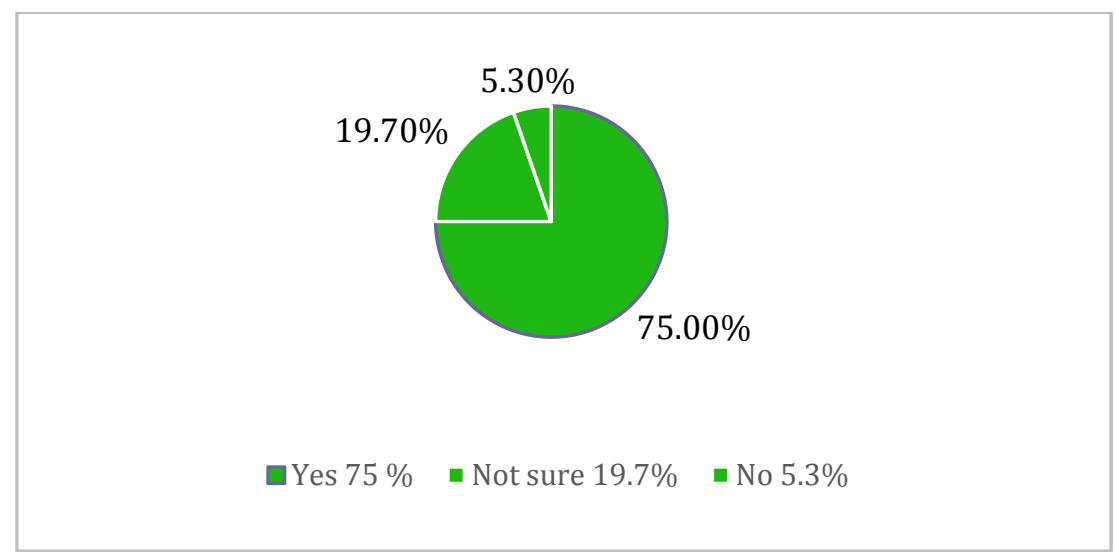

Figure no. 2: Do you know how to give first aid to a casualty?

To determine whether the respondents' self-confidence is based on knowledge, we have asked the following question: "In what proportion are the ventilations to compressions in CPR?".

The correct answer has been given by $79.8 \%$ of the respondents, which we evaluate as a very good preparedness and excellent awareness of how to manage a real situation and administer first aid.

We have examined the respondents' knowledge once again with a question: "What should the position of the casualty's head be in CPR ventilation?". $84.2 \%$ have given a correct answer, which again confirms the high awareness of the respondents.

The question "Have you been trained in medical first aid in the area of an accident?" has been answered positively by $62.9 \%$ of 228 respondents.

The self-evaluation of the respondents' ability to dress a wound is significantly lower $38.4 \%$ have responded affirmatively and $47.2 \%$ have hesitated and responded - partially.

The question: "What kind of a dressing has to be applied in case of arterial bleeding?" 
has been answered correctly by $41.9 \%$ of the respondents, which confirms the lesser knowledge of wound dressing and we evaluate that as a good preparation.

The correct answers to the question: "How long may a temporary arterial bleeding dressing last?" - for an hour in winter and an hour and half in summer - have been given by $39.5 \%$ and $38.1 \%$ respectively (Figure no. 3), which once again demonstrates the lower awareness and readiness to administer first aid by dressings.

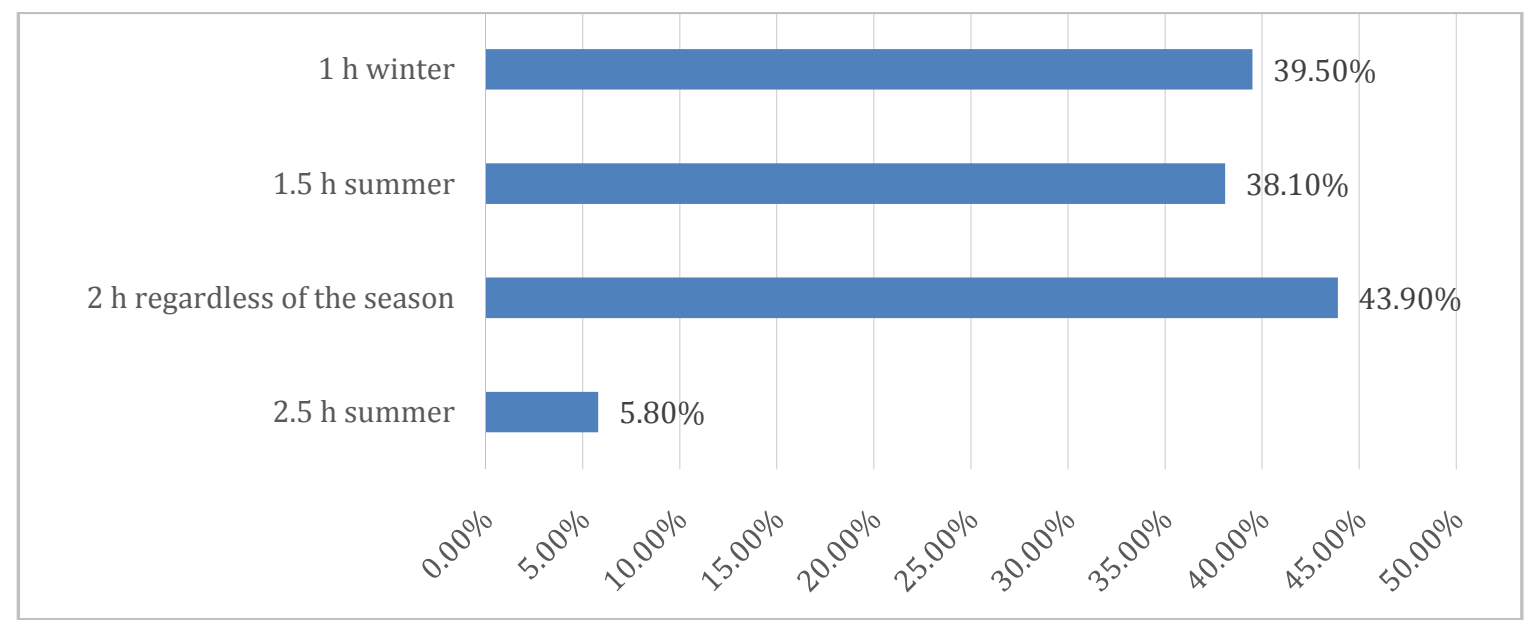

Figure no.3: How long may a temporary arterial bleeding dressing last?

The answers to the question: "How may a post-flood epidemic occur?" vary (Figure no. 4).

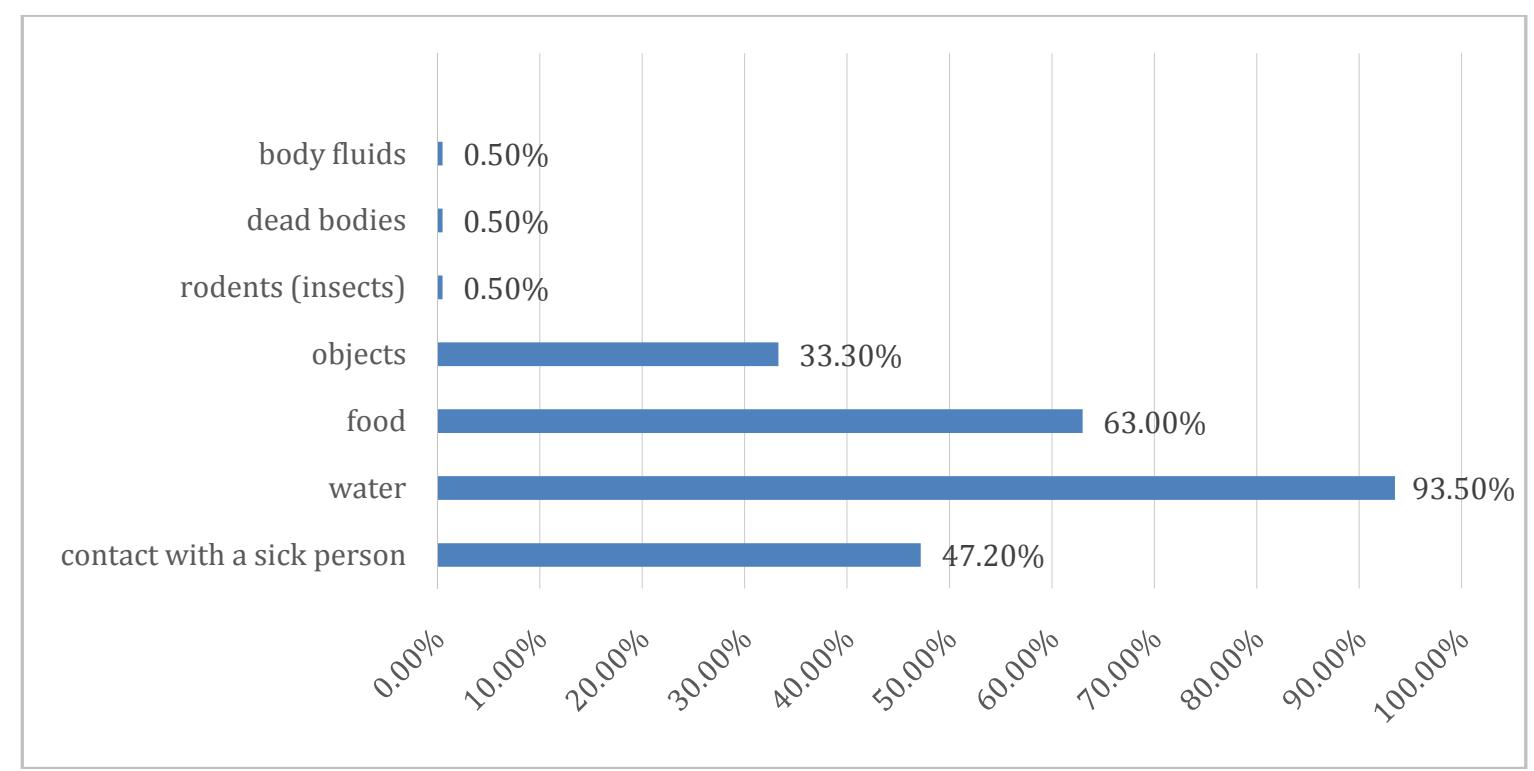

Figure no. 4: How may a post-flood epidemic occur?

Almost all participants in the research have responded that post-flood epidemics are transmitted through water $-93.5 \%$ and nearly $2 / 3(63 \%)$ - through food, about half of them $(47.2 \%)$ - by a sick person, just $1 / 3$ $(33.3 \%)$ - through objects and an insignificant number of them $(0.5 \%)$ have answered "by rodents (insects), dead bodies and body fluids".

We evaluate their knowledge about "water and food threat" as very good, compared with other possibilities for contamination. 
We have encountered an extremely low awareness and lack of knowledge of the possible actions in case of threat of an epidemic $-54.6 \%$ have answered that they would immediately leave the area, which poses a threat of spreading the epidemic, and only $7.9 \%$ would remain at home, which is the right decision.

The measures to be applied in case of intestinal contagious disease according to the surveyed group (229 respondents) are again quite well known $-86.5 \%$ regularly wash their hands, $80.3 \%$ use cleaning disinfectants, $66.4 \%$ apply good food processing and $80.8 \%$ - boil the water. Only $3.5 \%$ don't have any knowledge.

We can evaluate the knowledge of protection against airborne infections in cases of threat of epidemic as good $-60.7 \%$ would immunize themselves, $48.9 \%$ would seek medical help, $70.3 \%$ would use a cottongauze mask, 33,2 \% - frequent room ventilation, $45.4 \%$ - disinfection and only $3.9 \%$ do not know.

The respondents also have a good knowledge of the measures to prevent a postflood epidemic. We have received the following answers $-81.8 \%$ sanitation within the area, $57.8 \%$ - immunizations, $68 \%-$ information, $64 \%$ - guidelines for proper behavior and $64.4 \%$ - means of protection are needed.

The answers to flood protection selfassessment are quite modest - only $8.8 \%$ consider that they are prepared, $48.5 \%$ unprepared and $42.7 \%$ partially prepared.

Self-assessment of sufficient knowledge to protect from other disasters is similar $-21.1 \%$ consider themselves prepared and $78.9 \%$ unprepared.

Of 227 people answering the question "Can you swim?" $81.5 \%$ can and $18.5 \%$ can not, which calls for a very good readiness of the people against floods.
There have been no differences in education, gender and residence $(\mathrm{p}<0.05)$.

\section{Conclusions}

1. A high percentage of respondents have experienced a flood (42\%).

2. The majority of respondents $(64.6 \%)$ have not informed themselves whether they live in a flood area.

3. Self-assessment of respondents to administer first aid during floods is high (75\%), but overall preparedness for disasters is low because $78.9 \%$ consider themselves unprepared.

4. Evaluation of the awareness and readiness of the studied group of 230 young foreigners temporarily residents in Varna, Bulgaria is as follows:

- very good in administering first aid to a casualty with no breathing and no heart activity;

- with good knowledge of flood epidemic consequences; $80 \%$ will take effective measures against the risk of intestinal contagious disease and $81.5 \%$ will be saved from the flooding because they can swim;

- lower, but still good preparedness for wound and arterial bleeding first aid (close to $40 \%$ ), mechanisms of contamination transmission by means of objects $(33,3 \%)$, use of disinfectants in the case of epidemics $(45,4 \%)$;

- very low readiness for rapid evacuation in cases of floods and other disasters (only $5.3 \%$ have a bug-out bag);

- due to a lack of sufficient knowledge, $54.6 \%$ will leave the area during an epidemic, which will lead to the spread of the epidemic and will pose a serious danger to the health of a large part of the population.

5. There are no differences in education, gender and place of residence $(\mathrm{p}<0.05)$. 


\section{REFERENCES}

Khorram-Manesh, A. (2017). Handbook of Disaster and Emergency Management. Supported by DGECHO, Gothenburg, EU: Kompendiet.

Kostadinov, R. (2010). Drought and Community Safety. In Hristov, J., Kyriopoulos, J., Konstantinidis, T., \& Shipkovenska E. (Eds), Public Health and Health Care in Greece and Bulgaria (pp. 899-905). Athens, Greece: Papazisis Publishers, ISBN 978-960-02-2441-2.

Kostadinov, R. (2010). The Host Nation Health Care System Ambiguity in Medical Assessment. Military Medicine, Supplement, 10-13.

Krastev, K., \& Angelov, P. (2016). Integral Components Analysis of the Professional Readiness for Acting in Extreme Social Environment. Scientific Bulletin, Vol. 21, Issue 2, 97-101.

Kyuchukova, S., Peniovska, P., \& Radeva, N. (2017). Medical assistance in mass casualty accidents in Golden Sands Resort. Aviation, maritime and cosmic medicine. Part II Disasters, breakdowns and catastrophes, 41-46.

Radeva, N. (2019). Civil protection current aspects in disasters. Varna: Steno.

Romanova, H., Radeva, N., Marinova, I., Marinov, M., \& Bozova, T. (2012). Floods the most common disaster. Reasons, successions, organizational measures. Journal of Free University - Varna, Vol. XVII, Issue 2, 65-70. 